\title{
Poniente granadino. Hacia una marca de calidad territorial para espacios expositivos
}

El Grupo de Desarrollo Rural del Poniente Granadino ha elaborado la ponencia para el debate de una de las primeras cartas específicas de calidad rural vinculadas al sector cultural. En la propuesta establece su propio parámetro de óptimos, un total de 35 indicadores, para aquellos equipamientos expositivos que pretendan aspirar al distintivo Calidad Rural en este territorio de la provincia de Granada.

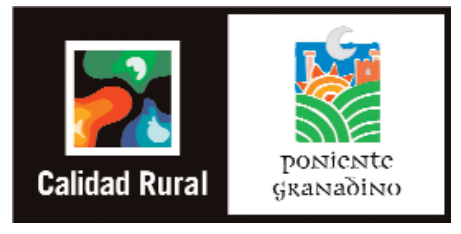

Por la marca Calidad Rural, los usuarios de productos y servicios generados en determinados medios no específicamente urbanos comenzamos a reconocer una imagen y una "filosofía de hacer" vinculada a ciertos criterios de autenticidad y sostenibilidad (económica, ambiental y social) nada desdeñables.

El concepto de calidad percibida, vinculado a la idea global del territorio rural europeo, se pone en práctica por medio de la marca territorial Calidad Rural, que en nuestro país agru-

- Museo de la Alcazaba de Loja (Sala Baja) / Fuente: ÁreA de Cultura del Ayuntamiento de Loja

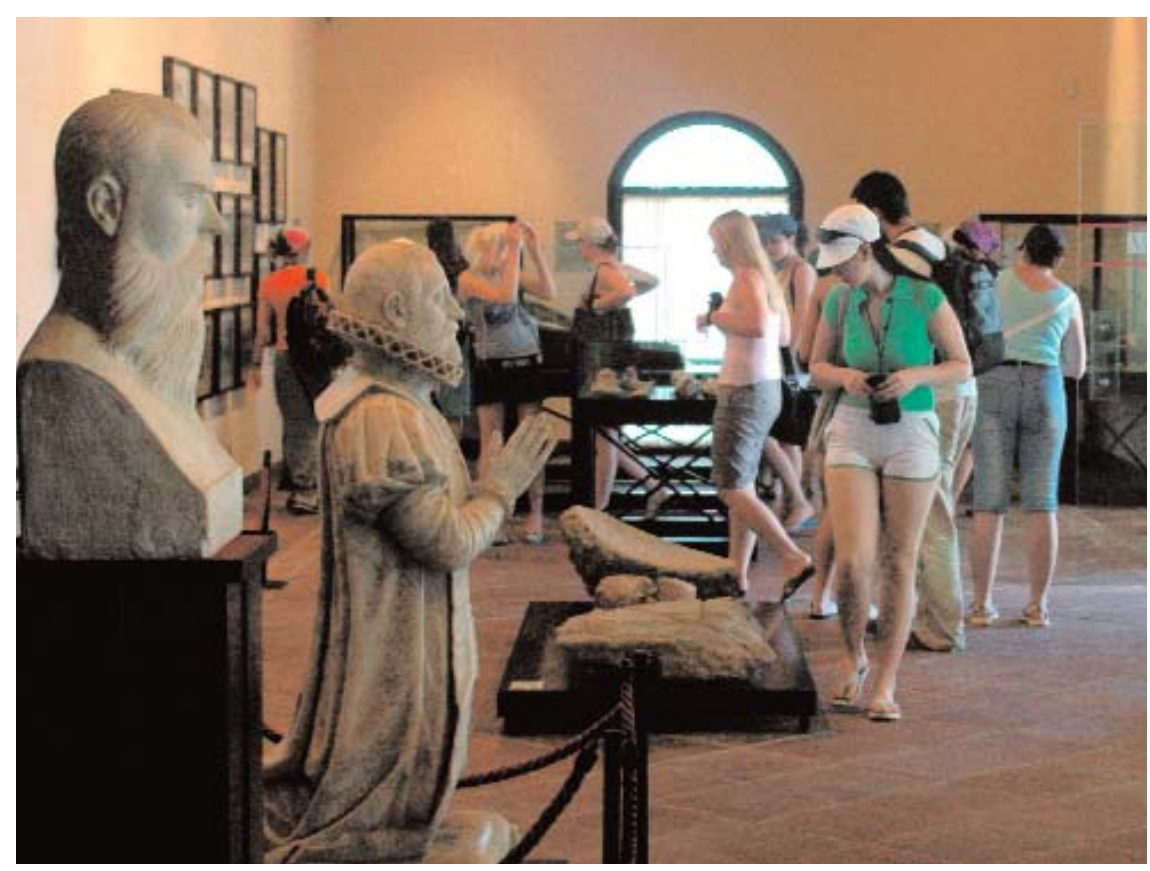

pa a una decena de comarcas articuladas en una red de cooperación de la cual forma parte integrante y activa el Poniente Granadino.

En este contexto de reflexión y diseño de los parámetros de excelencia específicos de bienes y servicios del mundo rural, sus distintos agentes sociales, económicos e institucionales -ya sean públicos o privados, colectivos o individuales- desde la especialización en cada sector de actividad y en el territorio, trabajamos por definir las normas de calidad (cartas específicas) de cada uno de los productos o servicios prestados en el contexto de la propia comarca.

De este modo, el Grupo de Desarrollo Rural del Poniente Granadino ha elaborado la ponencia para el debate de una de las primeras cartas específicas de calidad rural vinculadas al sector cultural, estableciendo su propio parámetro de óptimos, a partir del reciente contexto normativo andaluz en materia de patrimonio histórico y museos como punto de partida.

En la ponencia para la Carta de Calidad Territorial específica de Espacios Expositivos del Poniente Granadino se recogen un total de 35 indicadores referidos a la calidad del servicio y la gestión, así como a la calidad ambiental y social de los equipamientos existentes o por instalar en la comarca, ya nos refiramos a un museo, a una colección museográfica, centro de interpretación (o similar), o a una 
sala de exposiciones temporales (salas de arte o equivalentes).

Obviamente, ni que decir tiene que las pautas de excelencia definidas son adicionales a todo lo previsto en el conjunto legal y normativo vigente, motivo por el cual la solicitud de la Marca de Calidad Territorial será una opción voluntaria de las entidades peticionarias, que conllevará la aceptación de un conjunto de acuerdos de calidad de gestión aprobados por la Asociación para el DesarroIlo Sostenible del Poniente Granadino en el contexto del programa Calidad Rural, supervisados por su Comité de Gestión y Control de la Marca de Calidad territorial.

La carta específica tiene la vocación de establecer referencias de calidad objetivas que, a modo de reto auto-establecido, puedan contribuir a la mejora progresiva de los equipamientos museísticos y expositivos. Para ello define una serie de indicadores a través de los cuales se expresa la idea y el criterio de calidad que el Poniente Granadino desea para sus instalaciones expositivas, según la iniciativa y el acuerdo conjunto de sus propios agentes locales. Todo un ejercicio de compromiso con el territorio y con el futuro.

\section{Juan Alonso Sánchez Martínez}

Director de Cultura del Ayuntamiento de Loja Vocal GDR Poniente Granadino
- CiC El Pósito de Loja (Acceso a sala de exposiciones) / Fuente: Área de Cultura del Ayuntamiento de Loja

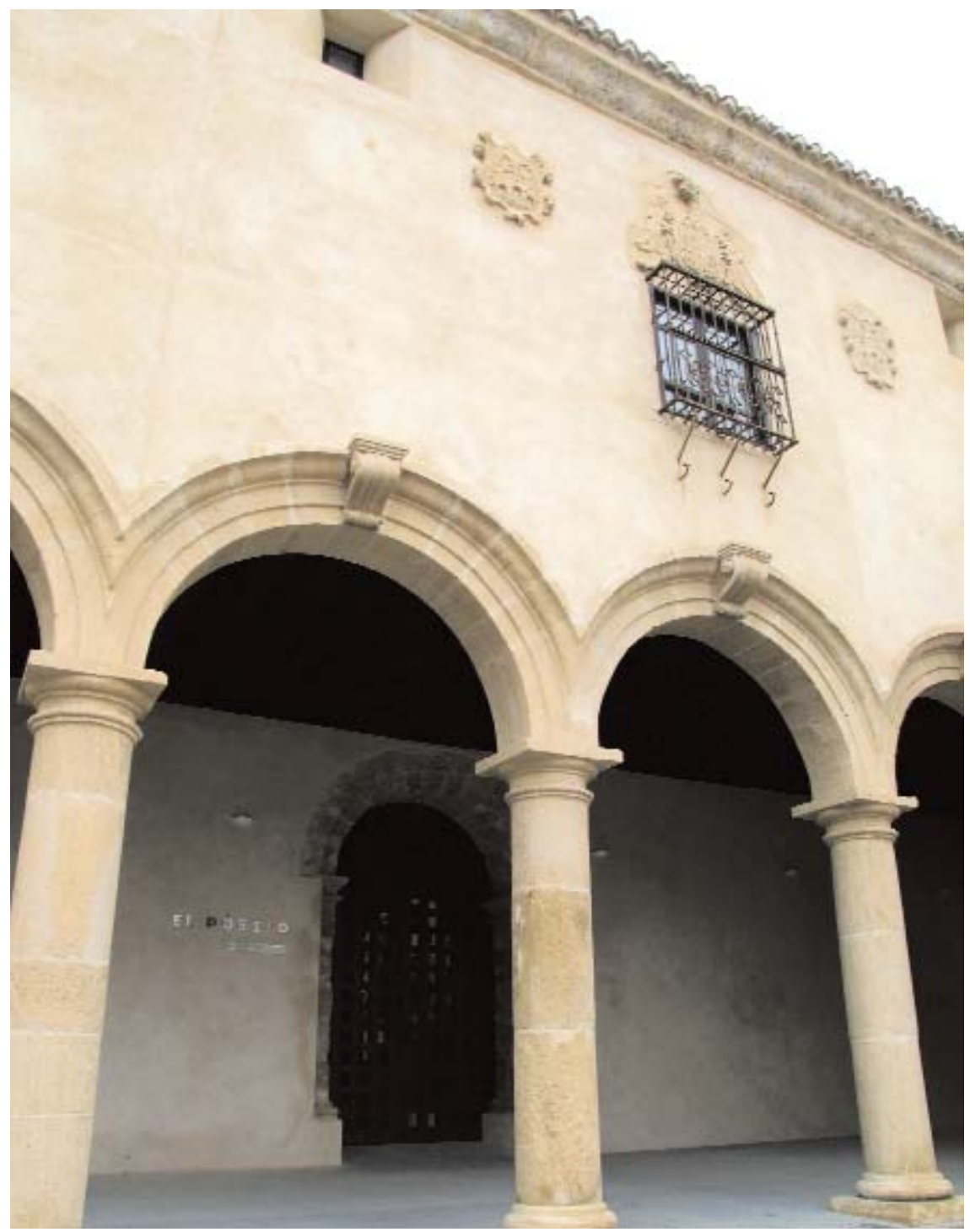

